\title{
GLL
}

Geomatics, Landmanagement and Landscape No. $4 \cdot 2019,7-22$

\section{PRECISE INTEGRATED HYBRID NETWORKS IN 21ST-CENTURY TUNNEL SURVEYING}

\author{
Henryk Bryś, Kazimierz Ćmielewski, Marek Trojanowicz
}

\begin{abstract}
Summary
The authors in this study briefly outline contemporary trends and the hierarchical construction of the models of surface and underground, horizontal tunnel networks, in the aspect of their optimization, accuracy as well as internal and external reliability. The developed modulartrilateral tunnel network is characterized by the elimination of the influence of temperature field on the measurement results, and also the resulting impact of the negative phenomenon of horizontal refraction occurring in the vicinity of the tunnel walls. Trilateration underground linear network with its specific advantages constitutes an alternative to traditional polygonal structures often used in the implementation of tunnel constructions. Simulation adjustment results and lateral coordinate deviations for the end points of the $10.5 \mathrm{~km}$ long network have been presented.
\end{abstract}

\section{Keywords}

tunnel surveying $\bullet$ hierarchical system of network construction $\bullet$ trilateral network $\bullet$ elimination of horizontal refraction

\section{Introduction and highlighting the problems}

Innovative measurement technology solutions are the locomotive of technical, economic and organizational progress. Contemporary tunnel surveying requires precise, reliable and functional implementation networks. Increasing the internal accuracy of angular measurements with the latest generation electronic total stations, since the introduction of the latest achievements in optoelectronics, with the simultaneous automation of the measurement process, has meant that the most significant source of tunnel measurement errors consists in systematic impact of the horizontal refraction field coupled with the induced distortions of light wave propagation. This is because the actual climatic and meteorological conditions of the measuring centre mean that the results of directions observations are burdened with errors two orders higher than the standard deviations reported by reputable geodetic equipment companies. In some specific cases, systematic direction errors in underground networks can be up to 10 mgon/500 m. The value of refraction effects is a function of such factors as: tunnel 
refractive index, horizontal gradient of refractive index, target length, positioning of the instrument and target relative to surrounding buildings, air flow rate, ventilation of the excavation, etc. The main factors shaping the refractive field include: air temperature, atmospheric pressure, and vapour pressure contained in the tunnel atmosphere, as well as horizontal gradients of these meteorological factors. In practice, the impact of instrument errors of contemporary total stations is incomparably smaller than the impact of the measuring centre in the tunnel space. Over the last 20 years, enormous progress has been made in the automation and digitization of geodetic instruments, as a result, leading to increasing the speed and accuracy of measurements in tunnel surveying and underground mining. Contemporary trends in techniques and new technologies for establishing and measuring surface and underground tunnel networks have been significantly modified and optimized. Classic tunnel measurements of the last century have changed enormously. Despite the enormous progress in the mechanization of drilling work with the aid of powerful modern mechanized shields, the so-called TBM (TUNNEL BOHR MASCHINE), the tasks of tunnel surveying still pose a huge challenge for tunnel construction industry. This applies in particular to special modular chain networks extend for by tens of kilometres. The implementation of tunnel structures currently up to $123 \mathrm{~km}$ in length (the planned DAILIAN-YANTAI underwater tunnel under the BOHAI gulf in CHINA) requires international cooperation of experts from many technical fields: Civil Engineering, Hydrogeology, Mining, Geology, Geotechnics, Geodesy, Geophysics, Computer Science, Geomatics, Rock Mechanics, Environmental Protection and Road and/or Rail Transport. A geodetic network should be understood as a constellation of measuring points stabilized by reinforced concrete columns or wall consoles, whose relative position in reference to each other has been determined by coordinates. The common geometrical database of all network points is called the reference system for a fixed zero measurement epoch (DATUM). When planning, designing and implementing surface and underground geodetic networks in tunnel construction, priority is given to: optimization of surface and underground networks, measurement process strategy, elimination of horizontal refraction phenomenon [Korritke 1992, Heister 1997, Bryś 2017], high accuracy of geodetic observations, and determination of internal reliability indicators changing with the length of the network. The above factors are decisive for the parameters of the a priori forecast of relative error ellipses in the location of the tunnel cluster points. The unscaled error ellipse is a statistical measure for the accuracy of determining the distance between two adjacent points of the tunnel axis cluster, for which the accuracy of the point location is described by the analysed error ellipse. Over the last two decades, increasingly ever longer and deeper communication tunnels have been designed and built, as long as over $2 \mathrm{~km}$ under the rock massifs. At the meeting in 2016, the President of Poland Andrzej Duda and the President of Slovakia Andrej Kiska [Bryś and Preweda 2018a], unanimously declared their intention to proceed with the construction of the "HIGH TATRA" railway tunnel between Zakopane-Kuźnice and Štrbské Pleso in Slovakia. According to the authors, based on photo interpretation of satellite images and studies of the local topography, the length of the tunnel should be about $18 \mathrm{~km}$. Construction 
of the tunnel and the 41 kilometre long railway line under the Tatra Mountains, Zakopane PKP-Poprad railway station, was already discussed by the governments of Poland and Slovakia in the interwar period, that is in the 1930s. As part of the "Three Seas Initiative", the international highway called "VIA CARPATIA" is currently under construction. The trans-European NORTH-SOUTH communication route will run from Lithuania (Klaipeda) through Poland, Slovakia, Hungary, Romania, Bulgaria to Greece (Thessaloniki). It is planned that the motorway, which is constructed in stages, will constitute the main transport route along the eastern borders of the EUROPEAN UNION. The "HIGH TATRA" railway tunnel will shorten the journey from Zakopane to Poprad by over one hour and it will enable an optimal connection with the international "Three Seas" route through Zakopane-Poprad-Presov-Košice, for travellers from Western Europe and Southern Poland. Long tunnels, that is above $2-3 \mathrm{~km}$ in length, are bored simultaneously from two opposite sides, with portal points (see Fig. 1) serving as starting points for underground network measurements and tunnel boring. Underground measurements mainly concern the setting out of the horizontal and vertical (height) direction of boring of the tunnel structure, with the use of the colossal, 100-200 meter long TBMs (tunnel boring machines). The decisive criterion for the accuracy of geodetic measurements and the setting of the tunnel axis is the so-called countershaft error, determined from the unscaled (relative) error ellipse. The present study is a continuation of the publication series [Bryś 2017, Bryś and Preweda 2018a, 2018b, Bryś 2018a, 2018b, Bryś and Preweda 2019], dealing with the issues of: minimizing horizontal refraction, measurement technology, and the process of coordinate equalization. The purpose of the present work is to familiarize Polish surveyors with contemporary trends in the implementation of geodetic tasks, covering the issues of measuring surface networks and long-chain tunnel networks. For the calculation of geodetic networks, many special utility calculation and compensation programs have been developed throughout the world. One of the problems is the optimal adjustment of the network geometry to specific geodetic tasks, as well as improving their variants, if necessary. For this purpose, data and information on the quality and reliability of the results of geodetic observations, as well as a priori determination of parameters of unscaled (relative) error ellipses are required [Bryś 2018]. This issue is not always a straightforward one; instead, it requires individual solutions for particular tunnel structures. Detailed studies on the above issues - i.e. TUNNEL GEODESY, have been discussed in the current literature on the subject, going back the last 25 years (see References).

\section{Hierarchical system of hybrid tunnel networks}

The tunnel network design is the first and central task in the implementation of long tunnels. Tunnel geodesy follows the geodetic principle "from the whole to the part" (general to specific), which has been in effect for decades. This means that the basic local GNSS network is superior to the angle-linear portal network and the implementation modular network (Fig. 1). 


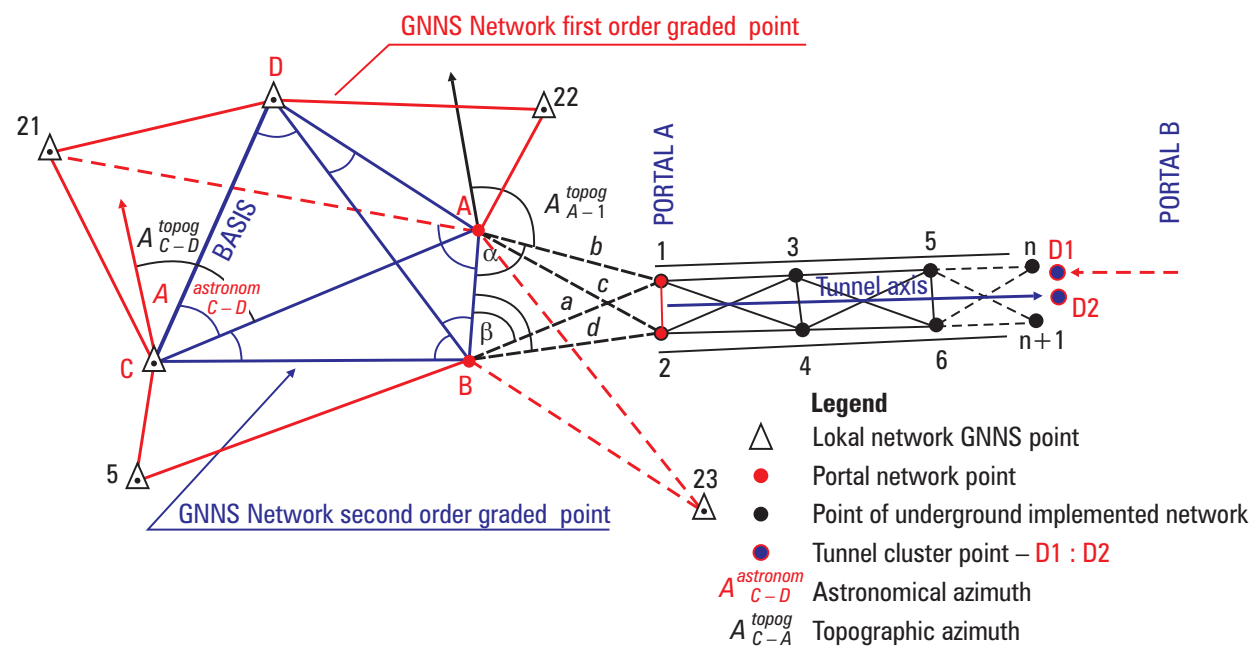

Source: Author's (Henryk Bryś) own study

Fig. 1. Hierarchical structure of a two-tiered, hybrid satellite-portal network

Local satellite networks are determined at a distance of one hundred to several hundred meters from the observation posts of portal network points on the construction site, i.e. in the foreground of portal A and the foreground of portal B of the tunnel in the reference system. On the basis of stationary, 24-hour GNSS measurements, the coordinates $X, Y, Z$ in the orthogonal Cartesian system are determined in a geocentric coordinate system (Geodetic datum) that is uniform throughout the area, with a strictly defined observation date, of the zero measurement epoch, that remains unchanged during the whole period of tunnel construction! Geodetic DATUM of hybrid surface networks means the location of a temporary coordinate system in relation to the Cartesian 3D system belonging to the global terrestrial reference system. The new DATUM must be adopted if it is necessary to re-measure surface networks as a result of destruction or displacement of concrete columns, and to conduct a new coordinate alignment - from the reference points (see Fig. 1), to the current tunnel boring site.

Coordinates in the global, geocentric coordinate system are determined based on GNSS measurements. The European Terrestrial Reference Frame (ETRF), which is part of the International Terrestrial Reference Frame (ITRF), has been established on a stable part of the Eurasian Plate (from the coast of Portugal all the way to the Urals). The Polish PL-ETRF89 and PL-ETRF2000 frames are mathematical and physical implementations of the European Terrestrial Reference System ETRS89. The physical implementation of the PL-ETRF2000 frame is a network of EPN stations (European Permanent Network) with accurately determined coordinates and their changes over time. Transfer and maintenance of this system in the territory of Poland takes place through the network of permanent stations of ASG-EUPOS (EUPOS Active Geodetic Network). 
Currently, many navigation systems are active, but those reference frames that are optimal for Central Europe include: GPS, Galileo, Glonass as well as the precise correction system called EGNOS (European Geostationary Navigation Overlay Service). By means of well-planned measurement campaigns, taking into account meteorological conditions that are changing in time and space, with simultaneous observations and introduction of tropospheric delay corrections [Dach et al. 2015]. Bernese GNSS Software Version 5.2], currently (2019), accuracy with standard deviations of the vector at the level of single millimeters $(1-2 \mathrm{~mm})$ is achievable with the application of the differential method. The goal of the European reference system was to minimize the ellipsoid coordinate variation over time. Satellite coordinates and astronomical/satellite azimuth, determined on different days and averaged, are then transformed into geocentric coordinates of Cartesian system $x, y, h$ of the national or regional topographic cartographic systems (for Poland, these are: the 1992 System, the UTM System and/or the 2000 System). The decisive factor ensuring the stability of surface tunnel networks is the proper and full recognition of topographic, geological and geotechnical conditions of their foundation and stabilization by means of massive, three to five meter, reinforced concrete columns with protective covers. Insufficient geological, hydrogeological, and geomorphological identification as well as the movement of transport vehicles may result in a seasonal, spatial displacement of these points, up to several millimetres per year. Therefore, annual control measurement campaigns are carried out, always in reference to epoch zero. CONTEMPORARY EARTH CRUST MOVEMENTS are also monitored in selected areas of the tunnel construction route (bridges, viaducts, dams, cities, etc.). Points of the local satellite network constitute a geodetic reference base for further development and establishing a subordinate portal network. Afterwards, calculations and analysis of the accuracy of satellite coordinates, obtained from measurement campaigns carried out simultaneously during static observations at satellite stations, follow as part of post-processing.

\section{Tasks of an integrated satellite-portal network}

The smallest reference unit of the geometric network constellation in Tunnel Geodesy is the portal network. The latter is used for direct transfer of azimuth or direction and coordinates of the Cartesian system, as well as the altitude to the implementation tunnel network (see Fig. 1). In order to obtain overtime observations, at least 4 portal network points are included in the integrated satellite-portal network. The configuration of the angle-linear portal network, together with the local GNSS network integrated therewith, is determined on the basis of detailed topography studies at the stage of tunnel construction planning. Its task is to ensure the highest accuracy possible of the determined coordinate points, and their reserve in the event of possible destruction by the movement of transport vehicles, from the vehicle traffic that continues around the clock. Portal network observation errors are transferred directly to the traverse network or to the modular-trilateral implementation network in the tunnel (see Fig. 4). In order to ensure the accuracy of 
coordinate and astronomical/satellite azimuth determination, as required by the investor of the tunnel's construction, the portal network points should be stabilized by observation columns at a distance of several dozen meters from the comparative base line C-D (see Fig. 1), serving for the determination of the astronomical azimuth with the aid of the super-precise gyrotheodolite (GIROMAT 5000). These points are fundamental to the accuracy and reliability of the entire hybrid tunnel network. To this end, frequent measurements of displacement and stability of observation columns are carried out, and in justified cases, particular points are excluded from the satellite-portal network. It should be emphasized that GNSS technologies and compensation procedures for hybrid surface networks often fail to provide the required standard deviations for determining the $x, y$ coordinates of $S_{x, v} \leq \pm 1.0 \mathrm{~mm}$. Depending on the measurement methodology, on the available instruments and software, and on the meteorological conditions and the weather, the variability of the determined satellite coordinates can range from single millimetres to as much as several decimetres. In case of any doubts as to the accuracy of measurements or the reliability of the network, classic supplementary measurements with the use of precision electronic total stations must be used: Leica Geosystems TCRPS $\left(S_{\alpha}=0.15 \mathrm{mgon}\right.$ and $S_{D}=0.5+1.0 \mathrm{~mm}$, industrial-grade total station NET05 Sokkia $\left(S_{\alpha}=0.15 \mathrm{mgon}\right.$ and $\left.S_{D}=0.8+1.0 \mathrm{~mm}\right)$ or other instruments of the same accuracy class. All observations and results of geodetic measurements, together with the calculation and compensation process, must be phased and monitored in order to ensure that they meet the stringent criteria of external and internal reliability of the network. However, in order to obtain high precision of observation for individual geodetic tasks, it is universally accepted that an independent construction or investor supervision team should be employed for the control assessment of major measurement tasks. This applies in particular to: transfer of azimuth and coordinates to the tunnel, control of the stability of observation columns and a comparative base for determining astronomical azimuth before each measurement campaign, etc. For all instruments and geodetic observations, the requirements must be met regarding valid meteorological standards and conditions and adjustments, and the accuracy analysis of measurement results must be performed.

\section{Control of the stability of satellite-portal network points}

The systematic movement of transport vehicles, heavy construction machinery and storage of reinforced concrete prefabricated elements on the foreground of the portal during the construction of the tunnel structure over a period of several years, all combine to cause spatial displacement of observation columns, and thus the values of the coordinates of the implementation matrix. Local, seasonal changes in coordinate values make their interpretation a complex and difficult task. The optimal method for checking the stability of points of a precise portal network is to compare the results of coordinate observations based on periodic multiple measurements of backward intersections, based on the local GNSS network for the epoch zero (Fig. 2). 


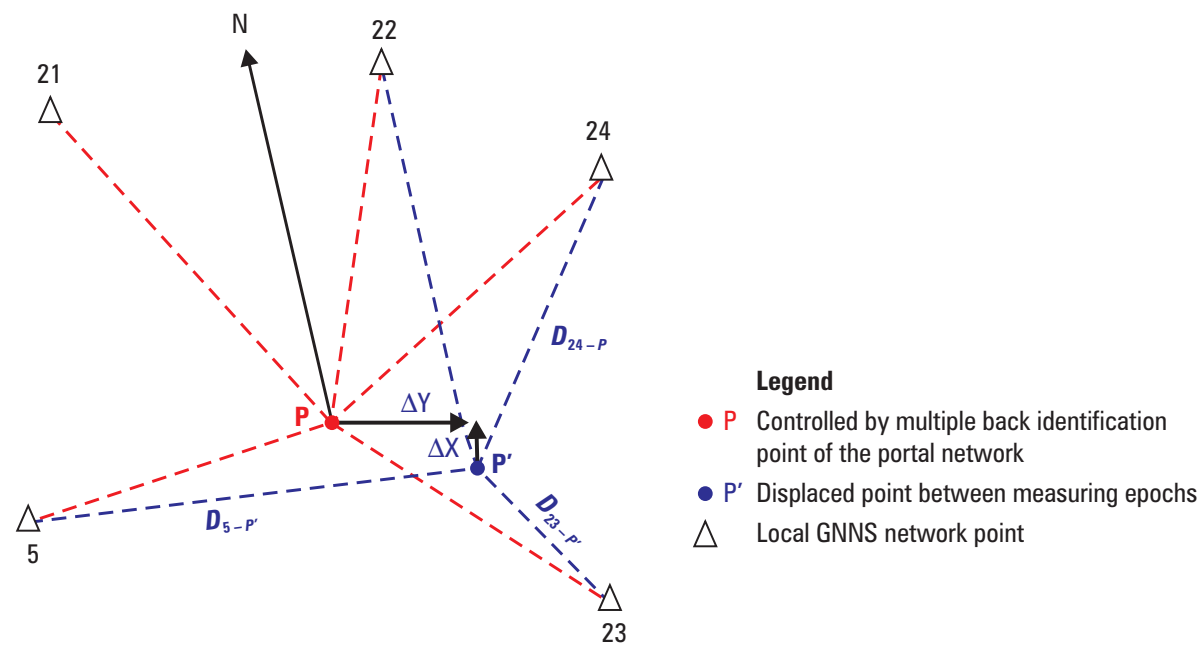

Source: Author's own study

Fig. 2. Periodic control measurements of point stability of the surface portal network, using an automatic digital total station

To this end, in order to check the stability of points $A, B, C$ and $D$, we measure directions and distances to points: 21, 22, 24, 23, and 5 (see Fig. 2) of the local GNSS satellite network. By means of the multiple "backward intersections" (back identification) from point $P$, we calculate the averaged coordinate value of the controlled point. If as a result of calculations, the coordinate increments $\Delta X_{p-p^{\prime}}$ and/or $\Delta Y_{p-p^{\prime}}$ exceed the value of \pm 3.0 then we conduct new, complete measurements of the angle-linear portal network, and carry out its alignment in order to obtain current azimuth binds. In subsequent phased adjustments of the underground network, we take into account the updated reference data. It should be emphasized that the displacement of the $P$ point with a value of $\pm 3.0 \mathrm{~mm}$, with an unfavourable displacement constellation and for a distance of $300 \mathrm{~m}$, may cause a topographic azimuth error by up to \pm 0.64 mgon (see Fig. 2), which results in a deviation of the last point of the implementation network with a length of 10.5 kilometres by the value of $Q_{X}=10.5 \mathrm{~cm}$ (see Fig. 6).

Table 1. Impact of the azimuth bind error on the value of $\mathrm{X}$ coordinate transverse deviation for the last point of the underground modular-trilateral network at $10500 \mathrm{~m}$

\begin{tabular}{|c|c|}
\hline $\begin{array}{c}\text { Topographic azimuth standard } \\
\text { deviation [mgon] }\end{array}$ & $\begin{array}{c}\text { Impact of incorrect topographic azimuth on the transverse } \\
\text { coordinate deviation at } 10500 \mathbf{m}[\mathrm{cm}]\end{array}$ \\
\hline 0.15 & 2.5 \\
\hline 0.30 & 5.0 \\
\hline 0.50 & 8.2 \\
\hline 1.00 & 16.5 \\
\hline
\end{tabular}




\section{Determination of reference points' coordinates of the underground tunnel network}

The optimum method for transferring topographic azimuth and coordinates from portal network points to the underground network is the "forward" intersection method. From points A and B with the highest coordinate accuracy, the following are determined in several series, with highest possible accuracy: angles Assuming, for example, the following data, and realistic standard deviations:

$\mathrm{A}-\mathrm{B}=\mathrm{D}=100.0000 \mathrm{~m}, \mathrm{~A}-1=\mathrm{B}-1=61.8034 \mathrm{~m}, \alpha=\beta=40^{g}, A_{A-1}^{\text {top }}=160^{g}, S_{\alpha}=$ $S_{\beta}=0.24$ mgon, $S_{X_{\mathrm{A}}}=S_{Y_{\mathrm{A}}}=S_{X_{\mathrm{B}}}=S_{Y_{\mathrm{B}}}=1.0 \mathrm{~mm}$ according to the law of error transfer, we obtain: $S_{X 1}= \pm 0.81 \mathrm{~mm}$ and $S_{Y_{1}}= \pm 0.24 \mathrm{~mm}$. The above standard deviations meet the accuracy requirements of contemporary geodetic tasks in tunnel construction. Taking into account the standard deviations of the determined coordinate points of the portal network, we ultimately obtain, for points 1 and 2 of the underground network: $S_{X 1}= \pm 1.31 \mathrm{~mm}$ and $S_{Y_{1}}= \pm 1.03 \mathrm{~mm}$. It should be stressed that, when transposing direction, the impact of the point coordinate errors, and of the observation errors is smaller for longer target distances than for shorter distances. In the case of transposing the direction towards the inside of the tunnel, to a traverse point located in its axis, observations should be made at late hours, on windless nights, for several consecutive days. The direction should be transposed from further points of the portal's matrix (from a distance above $100 \mathrm{~m}$ up to $200 \mathrm{~m}$ ), in a direction coinciding with the axis of the tunnel or parallel, but as close to its centre as possible. Failure to comply with the above cardinal rules may result in an error of shortening the direction by 5.0 mgon [Wilhelm and Mathias 1988], and as a result, an error of tunnel axis location at 10 kilometres of $Q_{X}^{N}=0,785 \mathrm{~m}$ ! Due to the occurrence of the phenomenon of horizontal refraction in the foreground of the portal, the observations of "forward intersection" need to be made after sunset or on a cloudy day, with complete cloud coverage of the sky, and measurements need to be repeated several times in the following days.

\section{Modular-trilateral implementation network}

Polygonal grids are the simplest matrices but, currently, they are exceptionally used in implementation measurements in tunnel construction. They can be used only for short tunnels up to 1-2 km long. Presently, suitable structures of implementation networks worldwide consist of combinations of modular angle-linear as well as linear networks [Bryś and Preweda 2018a]. The authors present an innovative hybrid-modular model of the trilateral network, published for the first time in [Bryś 2018 b]. Coordinates of modular tunnel network points constituted a permanent reference base for determining the mathematically defined, spatial axis of the structure. Particular advantages of this network include: elimination of the phenomenon of horizontal refraction, and high internal reliability coefficient. In a tunnel network, which is successively developing over a period of several years, only the distances of all sides of a given struc- 
ture are measured, using automatic electronic total stations, with a standard deviation of $S_{D}=0.8 \mathrm{~mm}+1 \mathrm{ppm}$ or with a more accurate device, such as Mekometer 5000 $\left(S_{D}=0.2+0.2 \mathrm{ppm}\right)$.

Theoretical vertex angles of $\beta^{\prime}$ (Fig. 3) are calculated from Carnot's equations with standard deviations of 0.05 to 0.2 mgon, depending on the length of the triangle sides, according to the principle of error transfer (1):

$$
S_{\beta^{\prime}}^{2}=\left[\frac{S_{D^{\prime \prime}}^{2}-\left(\frac{D^{\prime}-T \cdot \cos \beta^{\prime}}{D^{\prime \prime}}\right)^{2} \cdot S_{D^{\prime}}^{2}-\left(\frac{T-D^{\prime} \cdot \cos \beta^{\prime}}{D^{\prime \prime}}\right)^{2} \cdot S_{T}^{2}}{\left(\frac{D^{\prime} \cdot T \cdot \sin \beta^{\prime}}{D^{\prime \prime}}\right)^{2}}\right] \cdot \rho^{2}
$$

The symbols appearing in the formula (1) are in accordance with Figure 3. All meteorological adjustments (with regard to the air temperature in the tunnel, atmospheric pressure, and water vapour pressure in the air) are introduced into the measurement results.

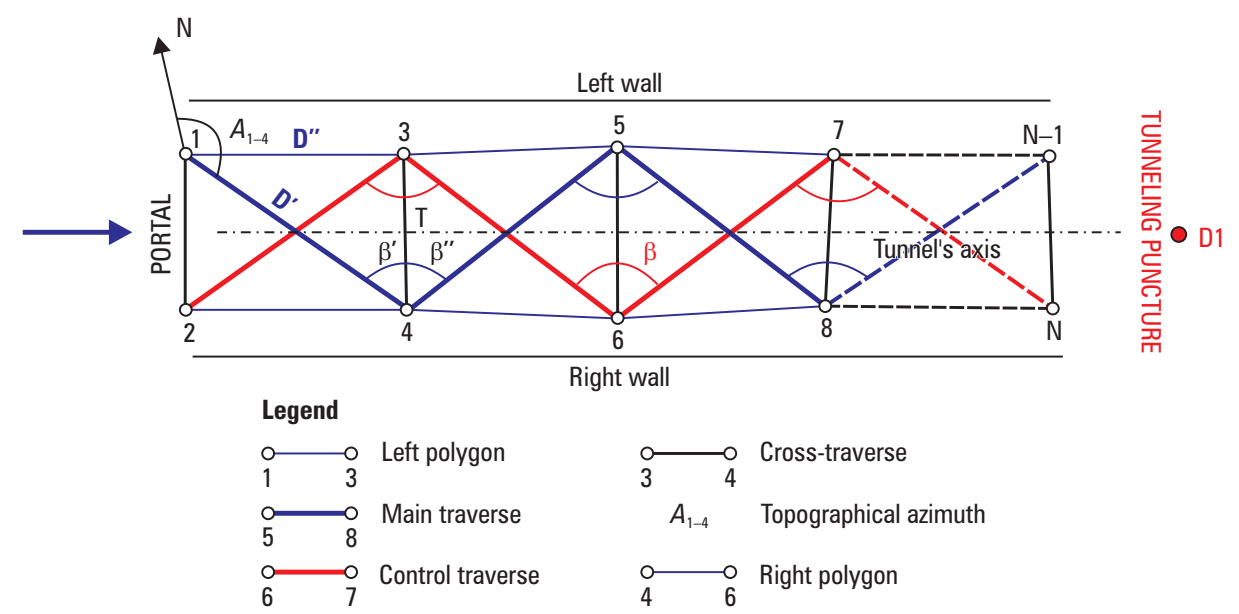

Source: Bryś 2018, drawing by the author

Fig. 3. Configuration of the innovative modular-trilateral tunnel network with the elimination of the horizontal refraction phenomenon

As a result of the simulation adjustments using the least squares method of the angle-linear network, horizontal displacements of coordinate points were obtained [Bryś and Preweda 2018a], whose synthetic values are presented in the diagram below.

The theoretical error of the axis meeting from two opposite directions of tunnel drilling is determined from coordinates of the last points D1 and D2, located very close, from unscaled error ellipses with the probability of $68 \%$ (see Fig. 1). 


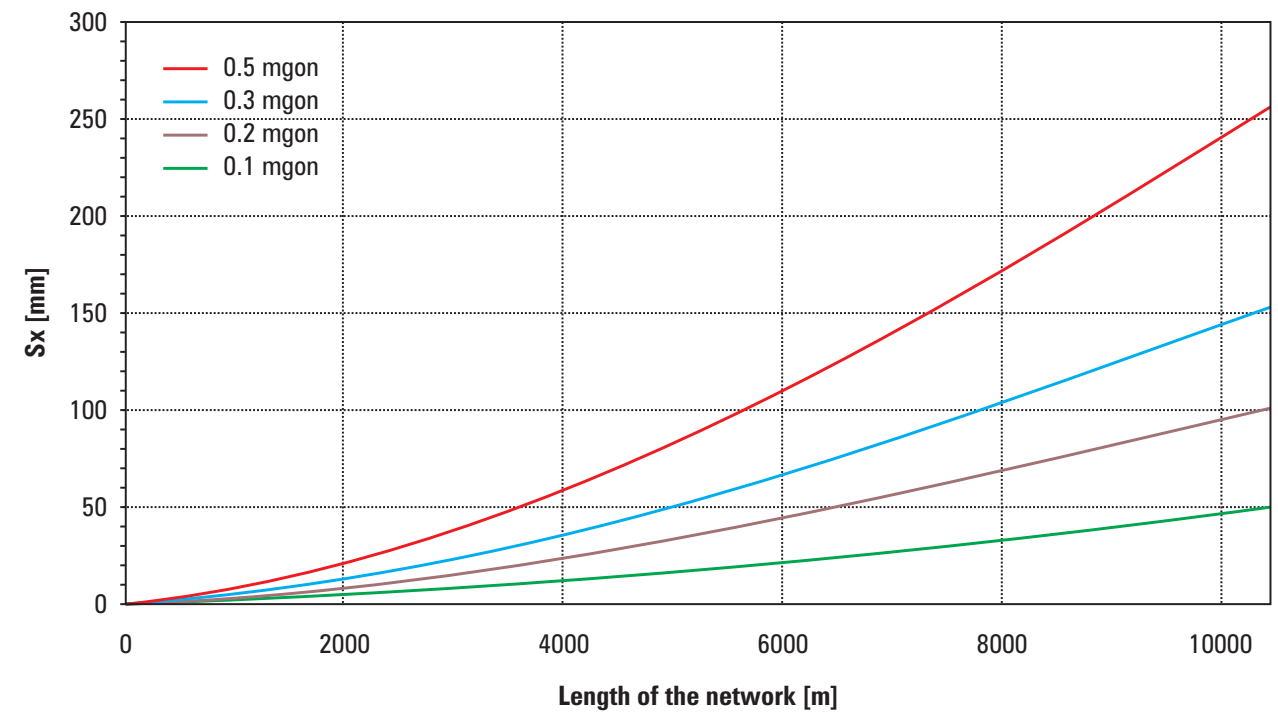

Source: Authors' own study

Fig. 4. Sample curves representing the course of the projected tunnel's axis, with standard deviations calculated a priori for the angle-linear network, with the probability of $68.27 \%$

\section{Impact of faulty input data regarding points of the portal network on the geometry of subterranean implementation network}

Due to incorrect reference data, incorrect transfer of topographic azimuth, and error of transfer of coordinate link points, the entire tunnel network gets twisted and displaced. The value of the lateral shift of the tunnel network points $Q_{\Delta X}$ shall vary depending on the value of the relocated azimuth of the reference (link) i.e. $A_{P^{\prime}-1^{\prime}}^{\text {top }}$ and distance L. The lateral deviation in the direction of the $\mathrm{X}$ axis - of the tunnel system, is determined from the following formula:

$$
\begin{gathered}
Q_{\Delta X}=\Delta X_{\left(N-1^{\prime}\right)-(N-1)}=\frac{\omega[\mathrm{mgon}] \cdot \mathrm{L}[\mathrm{m}]}{\rho[\mathrm{mgon}]} \\
\omega=A_{p^{\prime}-1^{\prime}}-A_{p-1}
\end{gathered}
$$

Let us assume that the $\mathrm{X}$ and $\mathrm{Y}$ coordinates of the point of reference $\mathrm{P}$ with tunnel point 1 were transferred with a $25 \mathrm{~mm}$ error, then the impact of this error on all network points will also be expressed by a $25 \mathrm{~mm}$ displacement error. In turn, the entire tunnel network is twisted and displaced, and the total value of displacement at the tunnel cluster location is $L_{\Delta Y}$ and $Q_{\Delta X}$. 


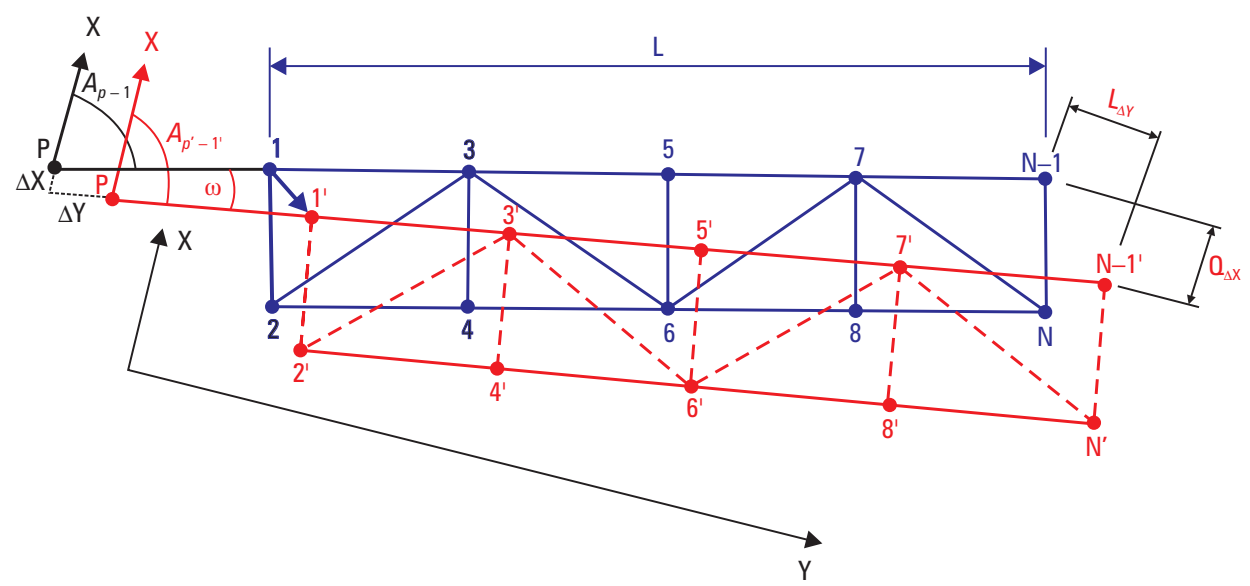

Source: formulated by the author, Henryk Bryś

Fig. 5. Compound effect of twisting and displacement of the modular tunnel network points, caused by the topographical azimuth transfer error and the shifting of the coordinates of point $\mathrm{P}$ (defect of network link data)

\section{Role and significance of reliability criteria and their application in the analyses of a modular-trilateral network}

The geodetic network is independent if measurement errors can be detected and eliminated. The paper presents only basic structures and measuring methods in the aspect of the hierarchical system of special tunnel networks construction. The basic criterion of confidence for surface and underground tunnel networks, and for their aligned coordinates, consists in dimensionless, internal and external RELIABILITY INDICES. These indices, as well as redundancy (overtime observations) are determined successively as the network expands, that is, in turn for individual subsequent network modules (see Fig. 3).

Source: Authors' own study

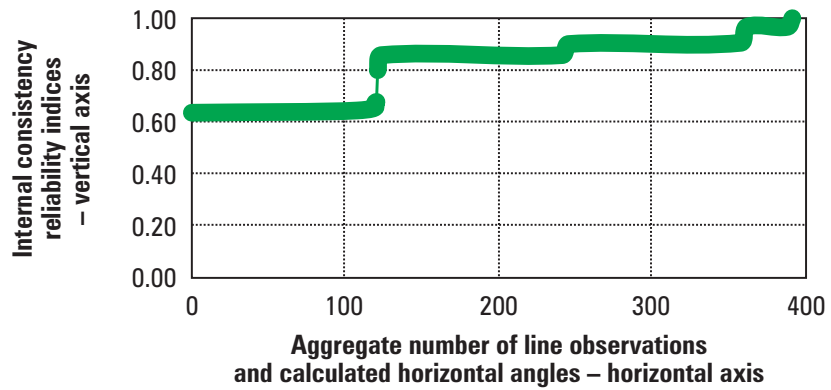

Fig. 6. Sample diagram of Internal Consistency Reliability Indices (WNW) for the simulated modular tunnel network (vertical axis - Internal consistency reliability indices, horizontal axis - Aggregate number of line observations and calculated horizontal angles) 
Characteristics of the modular trilateration network are as follows: $\mathrm{L}=10500 \mathrm{~m}$, $\mathrm{D}=350 \mathrm{~m}, \mathrm{~T}=15 \mathrm{~m}, \mathrm{~S}_{\mathrm{D}}=1.0 \mathrm{~mm}, \mathrm{n}=390, \mathrm{u}=120, \mathrm{~W}=\mathrm{nu}=270, \mathrm{~S}_{\beta}=0.2,0.3$ and 0.5 mgon [Bryś and Preweda 2019].

The Internal Consistency Reliability Index (WNW) of the tunnel network is a feature that determines the detection of unacceptable gross errors and systematic measurement errors in the observations, and their impact on the results of the process of aligning the coordinates of points of the network modules.

The External Consistency Reliability Index (WNZ) is a measure of errors that are transferred from the satellite-portal network to the aligned coordinates of the points of subsequent modules in the underground network (incorrect coordinates of tie points and/or incorrect topographic azimuth, see Fig. 5).

Redundancy (excess) means supporting results, enabling the use of statistical methods to ensure the required accuracy of distance observation. As a result of the a posteriori calculation and equalization process, overtime observations $\mathrm{W}$ enable disclosure of previously undiscovered observation errors at a given stage of measurements (for subsequent network modules). If there is an undetected gross or systemic error in the observations, then it is detected by the network. In that case, it must be cancelled by the observer, and the measurement needs to be repeated. We determine the Internal Consistency Reliability Indices from the square root of the diagonal elements of the reliability matrix [Preweda 2013, 2018]:

$$
\mathbf{R}=\mathbf{E}-\mathbf{A}\left(\mathbf{A}^{\mathrm{T}} \mathbf{A}\right)^{-1} \mathbf{A}^{\mathrm{T}}
$$

The theory of reliability of modern tunnel networks is closely related to the testing of statistical hypotheses regarding the results of the alignment and determination of the relative parameters of the (unscaled) error ellipses. In the geodetic practice of tunnel construction, STUDENT's T-test and distribution are commonly applied [Bryś and Preweda 2019]. For the planning, design and accuracy analysis of elongated tunnel networks, the following criteria of consistency/reliability indices are adopted [Derenbach et al. 2007]:

$0.1 \leq \mathrm{WNW} \leq 0.3$ sufficient network controllability,

$0.3 \leq \mathrm{WNW} \leq 1.0$ good and very good network controllability,

WNW - internal consistency reliability index.

The simplest and most effective way of detecting gross observation errors in tunnel networks is to ensure a sufficiently high WNW index (that is, above 0.5) during implementation of modular network measurements.

\section{A priori forecast of transverse deviations of the $x$ coordinate for a long tunnel network at the location of the countershaft}

Analyses of the results of measurements and statistical forecasts of unscaled error ellipses for the 10500 metre long modular-trilateration network between portals A and $\mathrm{B}$ demonstrate many advantages compared to traditional field-run networks and angle- 
line networks. The aggregate results of theoretical tests have been summarized in Table 2. Calculations and adjustments were made using the original, functional software of the equalization model (Author: Preweda), written in $\mathrm{C}^{++}$and MATLAB and published in Bryś and Preweda [2019]. Simulated observations in the tunnel network include measurement data between all network points and portal points of the underground part of the network.

Table 2. Standard deviation of the last $\mathrm{N}$ point of the analysed modular-trilateral network $S_{X_{\mathrm{N}}}$ [mm]

\begin{tabular}{|c|c|c|c|}
\hline $\mathrm{L}[\mathrm{m}]$ & $S_{\beta}=\mathbf{0 . 5}$ mgon & $S_{\beta}=\mathbf{0 . 3}$ mgon & $S_{\beta}=\mathbf{0 . 2}$ mgon \\
\hline 0 & 0 & 0 & 0 \\
\hline 1050 & 9 & 5 & 3 \\
\hline 2100 & 23 & 14 & 9 \\
\hline 3150 & 43 & 26 & 17 \\
\hline 4200 & 66 & 40 & 26 \\
\hline 5250 & 92 & 55 & 37 \\
\hline 6300 & 121 & 73 & 57 \\
\hline 7000 & 142 & 85 & 70 \\
\hline 8050 & 175 & 105 & 104 \\
\hline 10500 & 260 & 156 & \\
\hline
\end{tabular}

Source: Bryś and Preweda [2019]

On the basis of the calculations, adjustment results and statistical data, a theoretically identical common cluster point of the tunnel axis is determined from two opposite sides of the drill (D1 and D2), as well as the distance between them and the orientation of the relative error ellipse [Bryś 2018a]. The form and orientation of the relative error ellipse a priori depends on the network configuration and on the DATUM. For the confidence level, i.e. for the probability of network security, in the tunnel construction practice, the following is most often assumed: $\mathrm{P}=68.27 \%$ and $\mathrm{P}=95.45 \%$. The confidence level can be expressed as a percentage, for instance, $1-\alpha=95.45 \%$. For standard deviations of network coordinates with any probability, the standard deviations $S_{X_{N}}$ (see Table 2) should be multiplied by the quantiles of the STUDENT's $t_{\alpha}$ distribution, for $W=n-u$ degrees of freedom. For $\mathrm{P}=95 \%$, the quantile assumes the value of $t\left(1-\frac{\alpha}{2}, W\right)=t(0.975,250)=1.9695$. Quantiles were calculated using the software presented in [Preweda 2013, 2018].

It should be emphasized that with different standard deviations $S_{\beta}$ (see Table 2), the calculated values of transverse deviations $S_{X_{N}}$ for the trilateration network and for the "trailing" traverse (see Table 3) differ only slightly (insignificantly). This fact confirms 
the special characteristics of the innovative modular-trilateration tunnel network without the impact of the horizontal refractive field on distance measurements, and the WNW internal consistency reliability index increases with the number of points of the trilateral network (see Fig. 6) because the number of angles of the horizontal angles also increases. The modelling of the network's geometry makes it possible to increase the value of the internal consistency reliability index.

Table 3. Transverse deviations of the last points of the "trailing" traverse $\mathrm{L}=10500 \mathrm{~m}$ (Fig. 1), for different standard deviations of the top angle angles $S_{\beta}$, and standard deviation of the sides' lengths

\begin{tabular}{|c|c|}
\hline$S_{\beta}[\mathrm{mgon}]$ & $Q_{X_{N}}[\mathrm{~mm}]$ \\
\hline 0.2 & 107 \\
\hline 0.3 & 160 \\
\hline 0.5 & 267 \\
\hline 0.6 & 333 \\
\hline
\end{tabular}

\section{Conclusions}

- This study briefly presents the current trends in the construction of horizontal tunnel network models in the aspect of internal and external accuracy and reliability.

- The results of accuracy analyses, as well as statistical analyses and simulations of the construction of long modular surface and underground network models showed significant advantages in terms of accuracy and methodology.

- The modular-trilateral network presented herein is characterized by the elimination of the impact of the temperature field, and as a result, the phenomenon of horizontal refraction occurring in the vicinity of the tunnel walls. It is an alternative to traditional traverse constructs.

- The criterion adopted for the tunnel cluster forecast was the impact of stochastic errors in the measurement of side distances (lengths). The proposed configuration of the trilateral underground network is presented in the publication [Bryś and Preweda 2019].

- After the stage alignment of subsequent modules, subsequent topographic azimuths are calculated on the basis of network coordinates, which is necessary for the implementation of important, responsible measurement tasks: geodetic navigation of modern TBMs (tunnel boring machines), and staking out of tunnel axis points.

- Since the implementation matrix is being built successively over several years, along with the progress of drilling work, the results of the alignments provide the actual (as opposed to forecasted) a priori values for the coordinates of the particular modules in the underground implementation network. 
- Surveying measurements cannot be carried out without an independent control campaign, conducted by another team - for instance, one provided by an investor. The investor performs geodetic measurements independently. The surveying team affiliated with the construction management only performs control measurements occasionally.

- The observations are made solely with the accuracy postulated by ISO instructions and standards. The sides of the implementation network should be from approx. $150 \mathrm{~m}$ on curves up to $350 \mathrm{~m}$ on straight sections. Shorter sides allow for more accurate meteorological corrections for the measured sides of the network at tunnel depths up to over $2 \mathrm{~km}$.

\section{References}

Bryś H. 2017. Refraktionsmodelle in der hochpräzisen Ingenieurvermessung. Anwendungen in der industriellen Mestechnik. Geodäsie und Geoinformation Magazin, 1.

Bryś H. 2018a. Metoda wyznaczania rzeczywistych kątów refrakcji tunelowej w sieci modularnej. Przegląd Geodezyjny, 10.

Bryś H. 2018b. Modularno-trilateracyjna sieć tunelowa z eliminacją wpływu zjawiska refrakcji horyzontalnej. Przegląd Geodezyjny, 11.

Bryś H., Preweda E. 2018a. Problematyka refrakcji horyzontalnej w realizacyjnych sieciach podziemnych. Tunel kolejowy Polska-Słowacja „Wysokie Tatry”. Studium geodezyjne. Przegląd Geodezyjny, 2.

Bryś H., Preweda E. 2018b. Zur Beseitigung von Horizontalrefraktionseffekten in langen Tunnel-Netzwerken. Geodäsie und Geoinformation Magazin, 5.

Bryś H., Preweda E. 2019. Innovatives Modular-Trilaterations-Tunnelnetzwerk ohne Refraktionseinflüssen. Geodäsie und Geoinformation Magazin, 5.

Dach R., Lutz S., Walser P., Fridez P. (eds.). 2015. Bernese GNSS Software Version 5.2 User Manual. Astronomical Institute, University of Bern. https://doi.org/10.7892/boris.72297.

Derenbach H., Illner M., Veter M., Vielsack S. 2007. Ausgleichungsrechnung - Theorie und aktuelle Anwendungen. Universität Karlsruhe (TH). Schriftenreihe des Studiengangs Geodäsie und Geomatik.

Heister H. 1997. Experimentelle Untersuchungen zur Horizontalrefraktion im Tunnelbau. IX Intern. Geodätische Woche, Obergurgl. [In:] Institutsmitteilungen, Heft 17, Fachvorträge, Uni. Innsbruck, Institut für Geodäsie.

Korritke N. 1992. Horizontalrefraktion in langen Tunneln. XI Internationaler Kurs für Ingenieurvermessung. Zürich, Band 2, Paper IV/4, Dümmler Verlag, Bonn.

Preweda E. 2013. Rachunek wyrównawczy - modele statystyczne. Wydawnictwo Progress, Kraków.

Preweda E. 2018. Detailed horizontal geodetic control networks taking into account the accuracy of the reference points. International Multidisciplinary Scientific GeoConference SGEM, 18 , Geomatics, geodesy and mine surveying, 2.2. Informatics, geoinformatics and remote sensing, STEF92 Technology Ltd, Sofia, Bulgaria.

Wilhelm W., Mathias H.J. 1988. Empirische Bestimmung der Seitenrefraktion an 9 Objekten in der Praxis. [In:] Internationaler Kurs für Ingenieurvermessung, Dümmmler Verlag, Bonn. 
Prof. dr hab. inż. Henryk Bryś

Polska Akademia Nauk Oddział w Krakowie

Komisja Geodezji i Inżynierii Środowiska

e-mail: hbrys@pk.edu.pl

Dr. hab. inż. Kazimierz Ćmielewski, prof. UPWr

Uniwersytet Przyrodniczy we Wrocławiu

Instytut Geodezji i Geoinformatyki

ul. Grunwaldzka 53, 50-357 Wrocław

e-mail: kazimierz.cmielewski@upwr.edu.pl

ORCID: 0000-0003-4888-8531

Dr hab. inż. Marek Trojanowicz

Uniwersytet Przyrodniczy we Wrocławiu

Instytut Geodezji i Geoinformatyki

ul. Grunwaldzka 53, 50-357 Wrocław

email: marek.trojanowicz@upwr.edu.pl

ORCID: 0000-0001-9751-0389 